\title{
O QUADRILÁTERO FERRÍFERO - MG, BRASIL: ASPECTOS SOBRE SUA HISTÓRIA, SEUS RECURSOS MINERAIS E PROBLEMAS AMBIENTAIS RELACIONADOS.
}

\author{
Hubert Matthias Peter Roeser ${ }^{1}$; Patricia Angelika Roeser ${ }^{2}$.
}

\begin{abstract}
RESUMO
O fundador da Escola de Minas de Ouro Preto, o mineralogista Francês Claude Henrique Gorceix, definiu certa vez o estado de Minas Gerais como aquele com o peito de aço e o coração de ouro. Essa comparação vale em especial para o Quadrilátero Ferrífero $(\mathrm{QF})$, uma região clássica da geologia e da mineração brasileira, que se estende entre as cidades de Belo Horizonte (NW), Itabira (NE), Ouro Preto (SE) e Congonhas (SW). Ocorrem aqui jazidas de ferro $(\mathrm{Fe})$, manganês (Mn), ouro ( $\mathrm{Au}$ ), bauxita e pedras preciosas, como topázio e esmeralda. A área foi descoberta pelos bandeirantes no final do século XVII quando buscavam pela esmeralda, raridade sobre a qual circulavam na época colonial os boatos mais insanos. Entretanto, eles encontraram o ouro, e este era preto, motivo pelo qual a localidade do descobrimento passou a ser chamada de Ouro Preto. Os primeiros achados do metal nobre em torno de 1693 levaram a uma verdadeira febre aurífera. Houve naquele tempo uma migração enorme em direção às montanhas ao redor desse lugar, denominado inicialmente Villa Rica. E essa migração trouxe todos os seus aspectos positivos e negativos. Assim, antigas crônicas mencionam que no norte do país monastérios inteiros eram despovoados, porque também os monges foram atraídos pelo novo Eldorado. A procura dos aventureiros pelo metal nobre foi tão grande que a superpopulação da área causou em 1701 uma enorme emergência de fome, que suprimiu grande parte da população. Muitos morreram com os bolsos cheios de ouro, mas não havia nada comestível que pudesse ser adquiridos com seus tesouros. Uma vez que as ocorrências mais produtivas nos aluviões e sedimentos do rio do Carmo foram exploradas rapidamente, a febre aurífera chegou a um fim já após aproximadamente quarenta anos. Somente muito mais tarde surgiu na região a exploração subterrânea organizada do ouro. Como consequiência a região em torno de Ouro Preto perdeu muito de sua importância econômica, ainda assim a cidade permaneceu por muito tempo o centro administrativo de Minas e posteriormente foi promovida à capital do Estado. Com o reconhecimento geológico e a exploração das enormes ocorrências do minério de ferro na área do QF após a segunda guerra mundial, Minas Gerais viveu um renascimento econômico e transformou-se num dos estados mais ricos do Brasil. Ouro Preto com seu centro histórico bem conservado, suas igrejas barrocas ricas em ouro e obras de arte, seus museus, entre eles o bem conhecido museu mineralógico da Escola de Minas, e outros monumentos e aspectos interessantes se transformou em uma jóia turística nacional.
\end{abstract}

\section{INTRODUÇÃO}

O Quadrilátero Ferrífero, uma estrutura geológica cuja forma se assemelha a um quadrado, perfaz uma área de aproximadamente $7000 \mathrm{~km}^{2}$ e estende-se entre a antiga capital de Minas Gerais, Ouro Preto a sudeste, e Belo Horizonte, a nova capital a noroeste (Figura 1). É a continuação sul da Serra do Espinhaço. Seu embasamento e áreas circunvizinhas são compostos de gnaisses tonalítico-graníticos de idade arqueana (> 2.7 bilhões de anos).

Acima deste embasamento cristalino encontramse três unidades de rochas metassedimentares supracrustais: o supergrupo arqueano Rio das Velhas, o supergrupo proterozóico Minas e o grupo proterozóico Itacolomy.

O Supergrupo Rio das Velhas, composto de metassedimentos vulcanoclásticos, químicos e pelíticos, encontra-se discordante acima do embasamento e é considerado um cinturão de rochas verdes (greenstone belt). Neste supergrupo ocorrem as jazidas de ouro em sua paragênese clássica de sulfetos.

O supergrupo Minas que possui até 6000 $\mathrm{m}$ de espessura é composto principalmente de metassedimentos pelíticos e quartzosos e coloca-se discordante acima do cinturão verde Rio das Velhas. Dentre os seus quatro grupos, o de Itabira é o mais significativo em termos econômicos, contendo os minérios de ferro, localmente denominados itabiritos, internacionalmente conhecidos como banded Iron Formations (BIF's), minérios bandeados do tipo lake superior.O grupo Itacolomy é basicamente composto de quartzitos.

\section{RECURSOS MINERAIS}

O estado de Minas Gerais cujo sinônimo informal pode ser: "algo de cada", faz toda a honra ao seu nome. As minas de ferro e de manganês servem à indústria siderúrgica, a bauxita à produção de alumínio, 


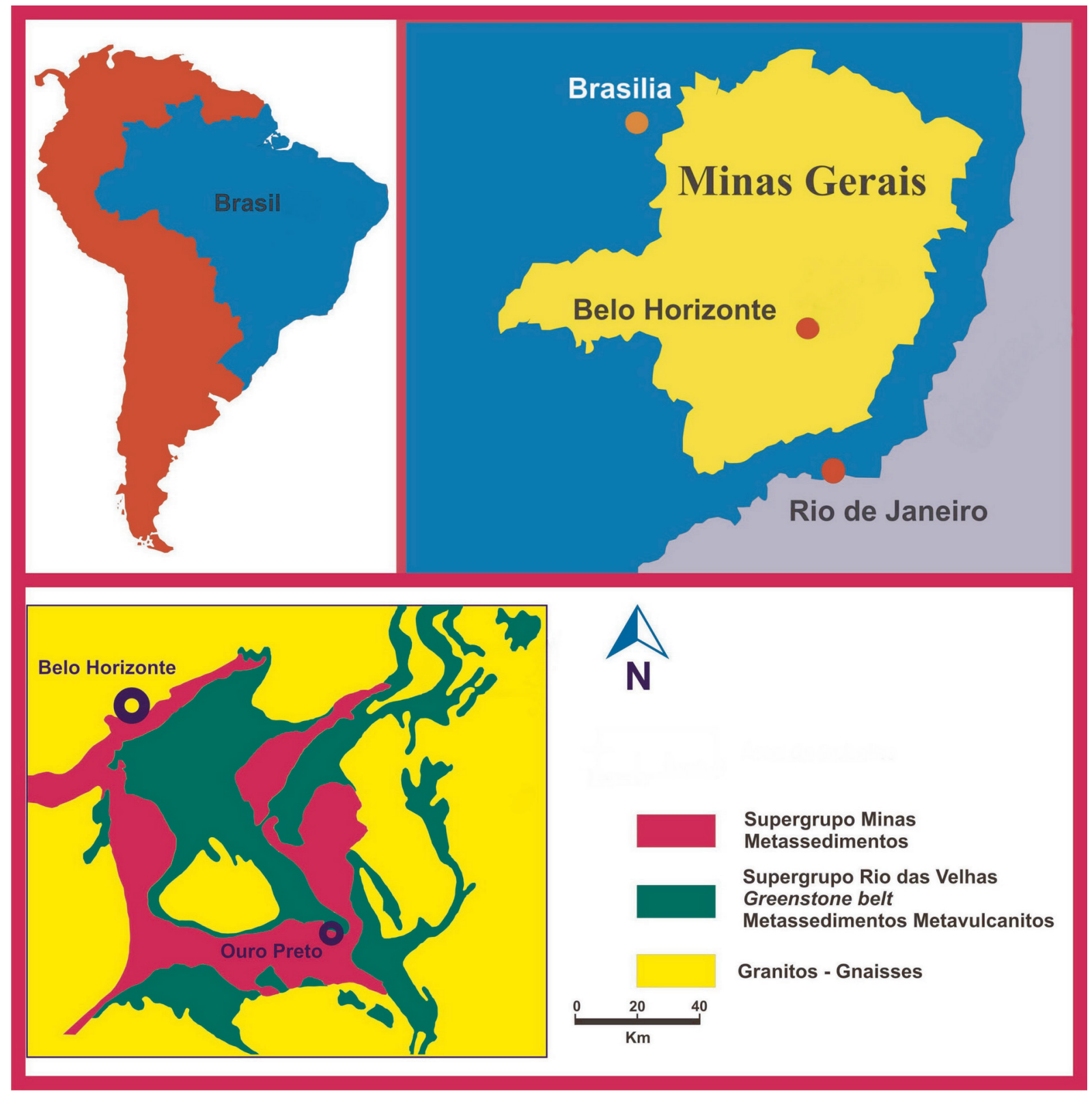

Figura 1. O Quadrilátero Ferrifero em Minas Gerais. Geologia simplificada segundo Dorr (1969)

Figure 1. The Quadrilátero Ferrifero of Minas Gerais State, simplified Geology second Dorr (1969).

o calcário representa a base da indústria de cimento, e rochas fosfáticas tem seu uso em fertilizantes. Rochas ornamentais como serpentinito e quartzito são aplicadas na construção civil e no nordeste do estado ocorrem pegmatitos industriais dos quais se ganha os minerais de muscovita e quartzo.

E não somente entre os insiders, mas mundialmente, o estado de Minas Gerais é reconhecido pelas suas gemas. Os pegmatitos da região de Governador Valadares fornecem turmalina, água-marina, morganita, amazonita e muitos outros minerais. A cidade de Ouro Preto está ligada além do ouro com a ocorrência de topázios imperais e desde o fim dos anos setenta do século passado são exploradas esmeraldas no nordeste do Quadrilátero Ferrífero. O rei das gemas deu mesmo seu nome a uma cidade no centro de Minas Gerais: Diamantina.
Pode-se assim considerar o estado de Minas Gerais como um paraíso mineralógico. Isto se aplica especialmente para o Quadrilátero Ferrífero. Até hoje, mais de cento e cinqüenta minerais puderam ser identificados nas vizinhanças diretas de Ouro Preto. Entre eles os mais comuns são plagioclásio, feldspato alcalino, quartzo, micas, anfibólios e piroxênios. Há minerais mais raros como cinábrio, estraurolita, cianita, almandina e pedras preciosas como ouro e topázio. Além disso, ocorrem os elementos do grupo da platina, e raridades de paládio $(\mathrm{Pd})$ como atheneita, estibiopalladinita. Ainda certos minerais foram encontrados pela primeira vez na região de Ouro Preto, p.e. a gorceixita, que homenageia o fundador da Escola de Minas e a Triphuyta do vale de Triphuy (hoje Tripuí) a leste da cidade.

Também não faltam curiosidades mineralógicas 
como o quartzito flexível (Itacolumito) e a liga de ouro e paládio (AuPd), até hoje ainda designada porpezita, cujo nome é um capítulo muito interessante da mineralogia.

Estas constelações geológicas levaram o mineralogista francês Claude Henrique Gorceix, a escolher a cidade de Ouro Preto para fundar uma Escola de Minas no Brasil em 1876, quando incumbido por Dom Pedro II. Nesta academia, integrada desde que 1969 com a Universidade Federal de Ouro Preto UFOP, desenvolvem-se há cerca de cento e trinta anos pesquisas nos campos da engenharias, em especial de mineração e geologia.

$\mathrm{Na}$ seqüencia são mencionados somente alguns dos recursos minerais mais importantes da área. Para estudos mais detalhados sugere-se a consulta de literatura especial.

\section{FERRO}

Os primeiros trabalhos geológicos sobre o ferro e as primeiras explorações foram realizadas em 1913 por Harder \& Chamberlin.

No caso dos minérios trata-se das $B I F^{\prime}$ s tipo lake superior que ocorrem exclusivamente no supergrupo Minas (Figura 2). Tais $B I F^{\prime}$ s mostram mundialmente

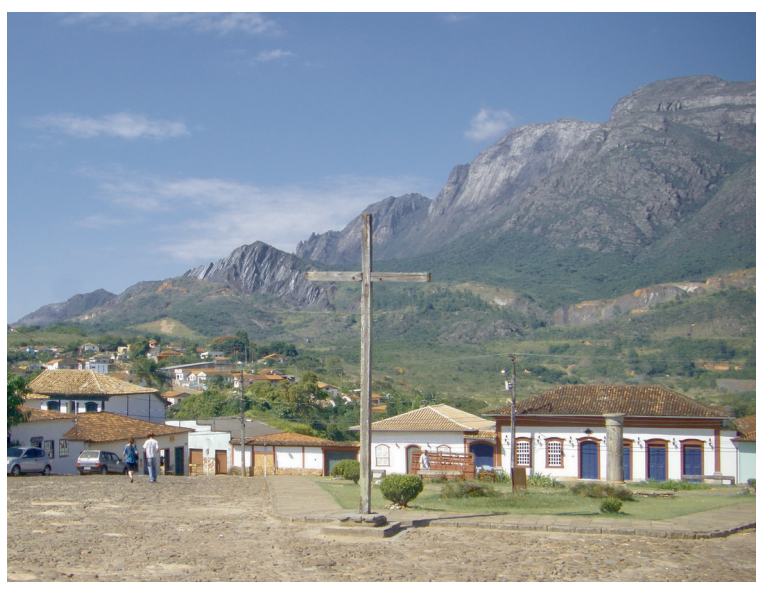

Figura 2. Ocorrência de itabirito próximo ao distrito de Catas Altas, ao pé da Serra do Caraça. Leste do Quadrilátero Ferrífero.

Figure 2. Occurrence of itabirite near the district Catas Altas, near the Serra do Caraça. Quadrilátero Ferrifero easte of the Quadrilátero Ferrifero.

a mesma estrutura rítmica de alterações entre camadas de óxidos de ferro e camadas de silicato ou também camadas de carbonatos. As espessuras dessas camadas variam entre $0.2 \mathrm{~mm}$ a aproximadamente $2.0 \mathrm{~mm}$. No QF dominam os minérios de fácies silicatada com os minerais hematita e quartzo, subordinadamente ocorrem minérios de fácies carbonatada com hematita e calcita/ dolomita. Os minérios do tipo Algoma são menos comuns. Suas ocorrências são limitadas ao supergrupo arqueano Rio das Velhas.
As ocorrências abundantes destas $B I F^{\prime}$ s fizeram do QF a maior jazida de ferro do Brasil durante as décadas de sessenta e setenta.

Atualmente encontram se cerca de trinta minas em exploração. A maior parte do minério é transportada via férrea ao porto de Vitória no Espírito Santo. Uma maneira quase única de transporte na America do Sul é realizada pela companhia SAMARCO hoje pertencente ao grupo VALE que bombeia a polpa de minério por um mineroduto de sua mina perto de Ouro Preto até a costa atlântica ao referido porto.

Se adaptando a necessidade do mercado internacional muitas das companhias de mineração produzem também as pellets. Os principais clientes dos minérios nacionais são China, Japão e o mercado europeu.

\section{OURO}

O coração de ouro das Minas Gerais mencionado por Henrique Gorceix deve ser considerado bem maior do que o peito de ferro, pois suas ocorrências são regionalmente muito mais distribuídas do que o ferro, indo além do QF. Na forma de ouro aluvional é lavrado ainda longe de suas ocorrências primárias nos corpos rochosos, distantes até mais de cem quilômetros fora do QF.

Do ouro primário (nas rochas) podemos diferenciar dois tipos. Ouro ocorre nas rochas quartzo-carbonáticas xistosas do supergrupo Rio das Velhas em paragênes clássicas com sulfetos de ferro (Pirita, $\mathrm{FeS}_{2}$ ), cobre (calcopirita, $\mathrm{CuFeS}_{2}$ ) e arsênio (arsenopirita, FeAsS). Além disso, o ouro encontra-se em zonas de falhamentos dentro dos itabiritos do supergrupo Minas. Aqui o ouro foi mobilizado de unidades inferiores (supergrupo Rio das Velhas), transportado na forma de complexos de cloro e reduzido nas camadas ricas em ferro a ouro elementar. Processos similares mobilizaram e transportaram de rochas básicas e ultrabásicas mais profundas o paládio. Encontrando-se ouro e paládio sob tais condições, pode se formar a mencionada porpezita (AuPd), típica para essa região.

Uma particularidade das pepitas de ouro existentes nos sedimentos de corrente dos corpos hídricos que atravessam Ouro Preto, era a sua coloração negra (Figura 3), que deu nome à cidade, inicialmente chamada Villa Rica do Albuquerque. Uma discussão detalhada sobre essa cor já existe na literatura. Menciona-se aqui somente que esta coloração não está relacionada ao paládio.

Um grupo de pesquisa da UFOP em cooperação com colegas da Universidade de Mainz na Alemanha já demonstrou em 1985 através de análises com microsonda, que os grãos do ouro preto devem sua cor a finas películas de óxido férrico que envolve as pepitas. Isso não surpreende, pois a maioria dos rios no $\mathrm{QF}$ possui hematita, goethita e magnetita abundantes, de maneira que materiais sendo transportados em corpos hídricos com tal composição sedimentar, ao longo do tempo desenvolvem esta camada escura de oxidação. 


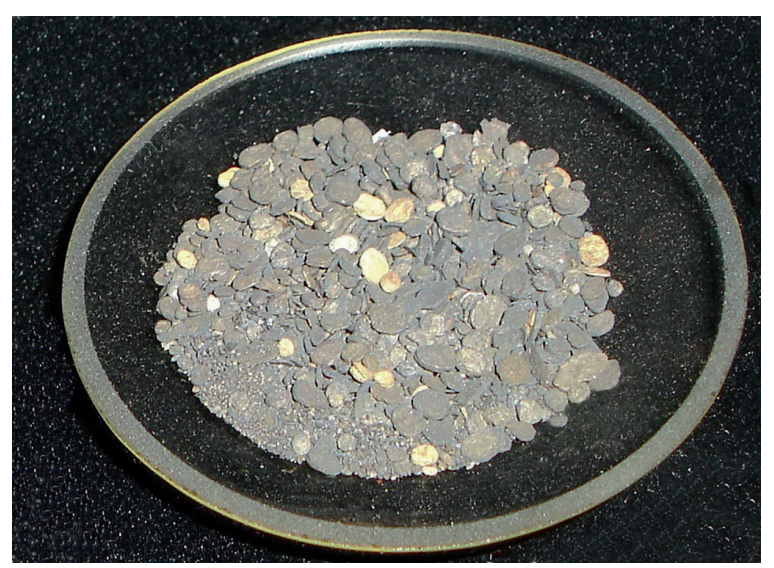

Figura 3. O ouro negro, que deu o nome à cidade de Ouro Preto.

Figure3. The black gold, which gave its name to the city of Ouro Preto.

\section{TOPÁZIO}

As ocorrências de topázio no QF são limitadas ao município de Ouro Preto. Elas encontram-se tanto ao Norte como ao Sul da anticlinal de Mariana. Geralmente relacionadas com mármores calcíticos ou dolomíticos, elas se apresentam em veios que possuem de alguns $\mathrm{cm}$ até $\mathrm{dm}$ em zonas de desdobramento. Tais zonas estão muito provavelmente relacionadas com um magmatismo rico em sílica conectado com eventos tectônicos terciáriocretáceos. Tanto as rochas vulcânicas primárias como as rochas metassedimentares, geradores dos topázios, se apresentam hoje intensamente intemperisadas. Os minerais quartzo, hematita, xenotima e topázio resistiram aos processos de alteração, permitindo que se realize nos dias atuais a lavagem das pedras preciosas dos solos.

O topázio de Ouro Preto apresenta-se geralmente em cristais prismáticos. Cristais de terminação dupla entretanto são muito raros. A cor tipicamente amarela que pode variar até o vinho-vermelho, já foi objetivo de numerosas investigações. Alguns trabalhos explicam a coloração como resultado de centro de cores em conexão com íons de cromo. Outros discutem teores de ferro e outros elementos cromóforos como vanádio, germânio e titânio. Mas uma indicação inequívoca falta até hoje.

Dentre as minas produtoras de topázio, que atuam paralelamente aos garimpos, estão a Vermelhão no bairro de Saramenha e a mina de Capão em Rodrigo Silva. A história da última é muito interessante. Três graduados da Escola de Minas da UFOP estudaram no começo da década de setenta do último século o relatório de viagem do cientista natural inglês MAWE de 1812. Seguindo em campo os detalhes descritos no relato encontraram a ocorrência de topázio no mencionado distrito ouropretano onde se fundou posteriormente a mina de Capão. Ela retira aproximadamente $400 \mathrm{~m}^{3}$ de material por dia do qual se ganha cerca de $40 \mathrm{~g}$ de topázio lapidável. As reservas calculadas da mina de
Capão estimam-se uma produção futura para mais do que dez anos.

As maiores peças encontradas até hoje são um topázio imperial de Rodrigo Silva, que pesou 504g e provavelmente é assim o maior topázio desta área. Em Antônio Pereira foi encontrado um topázio de $180 \mathrm{~g}$ e $13 \mathrm{~cm}$ de comprimento, que hoje se encontra no museu mineralógico da Escola de Minas da UFOP. Há cerca de quinze anos outra peça de $150 \mathrm{~g}$ foi encontrada no distrito de Antônio Pereira.

Conhecendo-se a história do mineral topázio na área de Ouro Preto, em especial os altos e baixos de sua produção, pode-se dizer que a última palavra relacionada ao mineral ainda não foi dita. Os solos e montanhas em torno de Ouro Preto reservam certamente ainda muitas surpresas em relação ao topázio.

\section{ESMERALDA}

É um aspecto curioso da história do Brasil, que o mineral, no século XVII responsável pela exploração do interior do país, tenha sido encontrado como um dos últimos minerais preciosos, somente em 1913 na Bahia. A descoberta de esmeraldas na Fazenda Belmont, próximo a Itabira, no nordeste do QF, no ano de 1978, abriu o ciclo da esmeralda“ também para o estado de Minas Gerais. Conta-se até hoje a história de um operário da linha férrea Minas-Espírito Santo, que cansado de buscar a água para beber longe de seu posto, decidiu furar seu próprio poço e desse modo se encontraram as primeiras esmeraldas das Minas Gerais. Existem outras versões em relação à descoberta das primeiras esmeraldas no estado, mas todas concordam que a pessoa que encontrou as primeiras pedras era um "leigo" em assuntos mineralógicos.

Porém, as últimas grandes descobertas deste mineral, como p.e. aquelas da mina Rocha na região de Itabira, devem a sua descoberta pela primeira vez às investigações geocientíficas sistemáticas.

Sabe-se que a gênese da esmeralda requer um "acidente geológico" por assim dizer, i.e. o encontro dos elementos cromo $(\mathrm{Cr})$ e berílio $(\mathrm{Be})$. Geralmente os dois não ocorrem conjuntos na natureza, sendo cromo um elemento ligado a rochas ultramáficas do manto e o berílio um elemento litófilo presente em rochas ácidas crustais. No nordeste do QF unidades de rochas meta-vulcânicas fazem contato com xistos ultramáficos, permitindo assim a formação da esmeralda.

Uma característica das esmeraldas da área de Itabira é a dominância de inclusões fluidas sobre os componentes minerais. Nas ocorrências da mina Rocha foi observada pela primeira vez uma característica eventualmente diagnóstica, um zoneamento de cor em formato de dentes de tubarão.

\section{PROBLEMAS AMBIENTAIS}

A temática de problemas ambientais existentes no QF mereceria um capítulo a parte. Aqui são apenas 
apresentadas algumas questões. Além de questões relacionadas ao meio urbano, como p.e., a falta de tratamento de esgoto em muitas vilas do $\mathrm{QF}$, a maioria dos impactos ao meio ambiente está de alguma forma relacionada com a exploração de recursos, principalmente atividades minerárias, dada a riqueza geológica regional. São observados basicamente dois tipos de impactos, aqueles ditos físicos e os de natureza química.

Desde os primeiros tempos de exploração eventos erosivos podem ser associados à mineração de ouro (Figura 4). Com o aumento das atividades de mineração, principalmente de ferro, impactos físicos aumentaram nos últimos quarenta anos. Mas pela legislação brasileira atual, as minerações devem

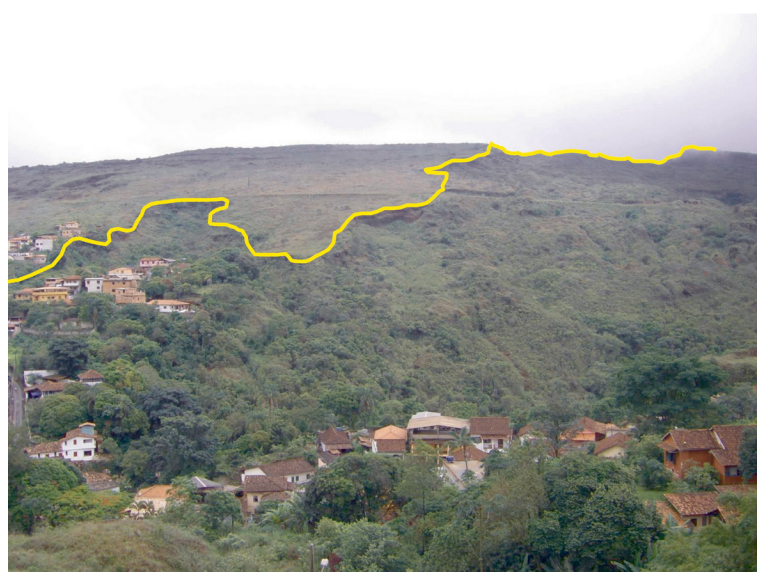

Figura 4. Processos erosivos no distrito de Passagem de Mariana, sudeste do Quadrilátero Ferrifero, resultado da exploração aurífera nos séculos XVIII e XIV.

Figure 4. Erosion in the district of Passagem de Marina, south-west of the Quadrilátero Ferrifero, result of gold exploration in centuries XVIII e XIV.

recuperar as áreas degradadas, e uma dessas formas de recuperação e o reflorestamento. Assim futuramente este tipo de impacto seria reduzido. Outro problema ligado à mineração de ouro, este de natureza química, é o fenômeno da drenagem ácida. Ela é resultado do intemperismo dos sulfetos que ocorrem associados ao ouro, quando expostos a condições de maior oxidação e drenagem. Tenta-se controlar nesses casos a acidez p.e. através de neutralização com $\mathrm{NaOH}$. Existem também técnicas de remediação passiva, como as wetlands. Ocorre que a drenagem ácida leva a mobilização de metais pesados que podem ser levados aos sistemas hídricos.

Outro caso especial de impacto químico está relacionado à concentração do ouro após sua lavagem na bateia, é a poluição por mercúrio nos garimpos. Oficialmente proibido é ainda largamente utilizados pelos garimpeiros.

\section{REFERÊNCIAS}

CARVALHO DA SILVA, J.; ROESER, U.; SCHULZ-DOBRICK,B.; TOBSCHALL, H.J. 1985. Ouro Paladiado of the mineralogical museum revisited; new electron microprobe analyses. III. Simp. Bras. Geoquímica, Boletim dos Resumos, página 9, Ouro Preto.

DA SILVA LOPES, P.H.; CESAR-MENDES, J.; ROESER, H.M.P. 2009. Einneues Smaragdvorkommen in Brasilien - Die Rocha Mineração Mine in Minas Gerais. Aufschluss 59:301-316. Heidelberg.

DORR, J.V.N. 1969. Physiographic, Stratigraphic and Structural Development of the Quadrilattero Ferrifero, Minas Gerais, Brazil. USGS. Prof. Pap. 641 - A, 110 páginas, Washington.

GANDINI, A.L.; BELLO, R.M.S.; CESAR, J.M.; ROESER, H.M.P. 2002. Imperialtopase aus Ouro Preto, G, Brasilien. Aufschluss, 53:151 - 158, Heidelberg.Gustavson em Roeser, H; Schurmann, K. 2009a. Die Geschichte des schwarzen Goldes (Ouro Preto) in Brasilien. Aufschluss, 59:273-294, Heidelberg. Harder,E.C.; \& Chamberlin, R.T. 1915. The geology of Central Minas Gerais, Brazil. Journal of Geology. part I. 23: 341 - 379, part II. 23:385 - 425.Roeser, H.; Schurmann,K. 2009. Brasilianischer Porpezit - ein Kuriosum aus der mineralogischen Namensgebung. Aufschluss, 59:295-300, Heidelberg.Roeser, H.; Schurmann, K. 1990. The black Palladiumgold of Ouro Preto: In: $15^{\text {th }}$ IMA MEETING, Beijing, China, Extended Abstr. p. 938-940. 